\title{
Training Of Young Badminton Athletes With The Uniba Cup I Championship
}

\author{
Wawan Setiawan', Puji Setyaningsih², Lutfi Irawan Rahmat ${ }^{3}$, Supono ${ }^{4}$ \\ 1, 2, 3, 4PGRI Banyuwangi University \\ Email: 1wawan11setiawan11@gmail.com, 2myedu37@gmail.com,3lutfiirawan04@gmail.com, \\ 4supono@unibabwi.ac.id

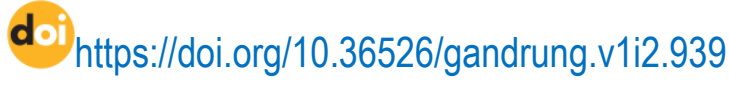

\begin{abstract}
Badminton is in great demand by the community both as a daily sport and chosen to be a professional sport by many young Indonesians. It is proven by the large number of badminton athletes sprung up both at the regional and national level. All athletes involved in badminton have one goal, namely to make Indonesia famous in the world. With the slowness of the achievements of Indonesian athletes and to better maintain the competition of badminton achievements in the international arena, then we PGRI Banyuwangi University intends to hold a Badminton Championship SMA / SMK / MA throughout Besuki Raya "UNIBA Cup I 2020". Our hope with this badminton championship can bring quality badminton athletes to Indonesia in general. In this championship activity we as a committee provide a place for young badminton players to achieve again in the future and become a means of proving for them in measuring their ability to play badminton. In our service activities we carried out several stages including the preparatory stages including the socialization of the badminton championship by distributing invitation letters and championship brochures to SMA / SMK / MA throughout the Besuki residency. Next to record the players who have registered and the last is a technical meeting, after that the implementation stage of the championship is held for 5 days and the last is the final evaluation stage, namely making the final report. Based on the results of devotion activities that have been carried out, (1) players get the right place to maximize the player's psychology in competing and improve and measure the technical abilities possessed by players, (2) The trainer indirectly has a picture of how psychological conditions and abilities possessed by the players, so that they can determine the right formula in the next training program, (3) for the committee who are Penjaskesrek students, where they certainly get lessons in managing a championship and participate in the refereeing process.
\end{abstract}

Keyword: championship, badminton, athlete, physical and psychological.

\section{Pendahuluan}

Olahraga bulutangkis adalah salah satu olahraga yang cukup popular di Indonesia bahkan di dunia. Bulutangkis adalah suatu permainan yang tidak dipantulkan dan harus dimainkan di udara sehingga permainan ini merupakan permainan cepat yang membutuhkan gerak reflek yang baik dan tingkat kebugaran yang tinggi (Pratomo, A. dkk, 2103). Memang untuk mencapai prestasi yang tinggi tidaklah mudah. Syarat-syarat bibit pemain bulutangkis yang baik antara lain dipenuhi syarat fisik, yaitu kesehatan yang baik tidak dimiliki cacat tubuh, postur tubuh tinggi, dimiliki unsur kondisi fisik yang baik (kekuatan, kecepatan, kelincahan, daya tahan, koordinasi, kelentukan, power) dan secara fisiologis 
dimiliki kemampuan kerja otot yang baik (Wijaya, A. 2017). Apabila seseorang ingin mencapai sesuatu prestasi optimal perlu dimiliki empat macam kelengkapan yang meliputi: (1) pengembangan fisik, (2) pengembangan teknik, (3) pengembangan mental, (4) kematangan juara

Bulutangkis sangat diminati oleh masyarakat baik itu dijadikan olahraga sehari-hari maupun dipilih untuk dijadikan olahraga professional oleh banyak anak muda Indonesia Terbukti dengan banyaknya bibit atlet bulutangkis bermunculan baik di daerah maupun tingkat nasional. Seluruh atlet yang berkecimpung dalam olahraga bulutangkis mempunyai satu tujuan yaitu mengharumkan nama Indonesia dikancah Dunia. Saat ini pebulu tangkis Indonesia masih mengalami penurunan pretsasi, prestasi Indonesia masih dibawah atlet negara Tiongkok bahkan mulai dilampaui negara Korea Selatan, Jepang dan Malaysia.

Berdasarkan permasalahan diatas maka diperlukan wadah bagi pemain maupun pelatih untuk memperkaya penagalaman bermain dari pemain dan membantu pelatih mengetahui kemampuan bermain dari pemainnya. Dengan hal tersebut diharapkan dengan diadakannya kejuaraan bulutangkis akan menjadi ajang menambah mental bertanding pemain dan sebagai bahan kajian pelatih untuk mengukur prestasi dari pemainnya.Dengan kemorosotan prestasi atlet Indonesia dan untuk lebih menjaga persaingan prestasi buutangkis di kancah Internasional, maka kami Universitas PGRI Banyuwangi berniat mengadakan Kejuaraan Bulutangkis SMA/SMK/MA Se-Besuki Raya "UNIBA Cup I 2020 ". Harapan kami dengan adanya kejuaraan bulutangkis ini dapat memunculkan atlet bulutangkis yang berkualitas untuk negara Indonesia pada umumnya.

\section{Metode}

Berdasarkan permasalahan yang sudah dijelaskan di atas maka ada beberapa metode yang dilaksanakan pada saat pengabdian yaitu :

1. Bekerja sama dengan kampus UNIBA Banyuwangi untuk mengadakan kejuaraan bulutangkis.

2. Mengajak serta mahasiswa yang berkompeten dalam cabor bulutangkis untuk menjadi panitia dalam kejuaraan bulutangkis.

Pelaksanaan pengabdian dilakukan mulai tanggal 05-13 Juni 2019. Adapun susunan kegiatan adalah sebagai berikut :

Tabel 1. Agenda Kegiatan

\begin{tabular}{lll}
\hline No & Kegiatan & Tanggal Pelaksanaan \\
\hline 1 & Pembukaan kejuaraan bulutangkis dan & 4 Februari 2020 \\
& pertandingan babak 64 besar putra & \\
\hline
\end{tabular}


GANDRUNG: Jurnal Pengabdian Kepada Masyarakat ISSN: 2721-6136 (Online)

\begin{tabular}{lll}
\hline $\mathbf{2}$ & Pertandingan babak 32 besar putra & 5 Februari 2020 \\
\hline $\mathbf{3}$ & Pertandingan babak 16 besar putra dan putri & 6 Februari 2020 \\
\hline $\mathbf{4}$ & Pertandingan babak 8 besar putra dan putri & 7 Februari 2020 \\
\hline $\mathbf{5}$ & Pertandingan babak semifinal dan final putra & 8 Februari 2020 \\
& dan putri serta penutupan kejuaraan. &
\end{tabular}

\section{Hasil dan Diskusi}

Berdasarkan hasil kegiatan pengabdian yang sudah dilaksanakan, pemain dan pelatih mendapatkan wadah yang tepat untuk memaksimalkan psikologi pemain dalam bertanding serta meningkatkan dan mengukur kemampuan teknik yang dimiliki oleh pemain. Dalam sebuah pertandingan tentunya pemain memiliki psikologis yang berbeda-beda. Dengan pemain mengikuti sebuah kejuaraan maka secara tidak langsung mengasah psikologis pemain agar terbiasa menghadapi sebuah pertandingan. Sebagai seorang pemain yang memiliki tuntutan untuk berprestasi saat bertanding, kecemasan bertanding pada atlet menjadi salah satu kondisi yang sering dialami pemain yang memengaruhi penampilan pemain dalam menghadapi pertandingan (Maulana,Z \& Khairani,M.2017)

Pelatih secara tidak langsung mempunyai gambaran bagaimana kondisi psikologis dan kemampuan yang dimiliki oleh pemainnya, sehingga bisa menentukan formula yang tepat dalam program latihan selanjutnya. Pembinaan atlet yang harmonis antara fisik dan mental sangat perlu untuk mencapai prestasi yang maksimal. Peningkatan kemampuan fisik, teknik dan taktik tanpa disertai pebinaan mental yang baik akan mengakibatkan hasil negative (Jamaliah,N dkk.2015). Peran serta dari kejuaraan yang sudah dilaksanakan tentunya berimbas pula bagi panitia yang merupakan mahasiswa Penjaskesrek, dimana mereka tentunya mendapat pembelajaran dalam memanjemen sebuah kejuaraan dan berperan serta dalam proses perwasitan.

Pada setiap pertandingan olahraga banyak faktor yang memengaruhi performa atlet dan akan memengaruhi prestasinya, diantaranya adalah faktor fisik dan mental (Pradnyaswari dan Budisetyani,2018). Kegiatan kejuaraan ini sangat penting dilakukan sebagai kegiatan melatih pemain untuk lebih terbiasa menghadapi situasi pertandingan. Dengan lebih banyak nya pertandingan yang diikuti oleh pemain maka akan lebih memudahkan mereka pada saat mengikuti kejuaraan yang lebih tinggi lagi levelnya. Selain itu juga kejuaraan yang diikuti ini menjadi tolak ukur dari buah kerja keras mereka dalam melakukan latihan sebelum pertandingan. Hal ini sangat bagus bagi perkembangan pemain muda khususnya dalam cabor bulutangkis.. Dan yang terpenting dalam kejuaraan kali ini seluruh pertandingan berjalan secara baik dan lancar tanpa ada kendala apapun, terlebih tidak ada pemain yang 
GANDRUNG: Jurnal Pengabdian Kepada Masyarakat ISSN: 2721-6136 (Online)

mengalami cidera dalam kejuaraan tersebut.

\section{Kesimpulan}

Kegiatan pendampingan tersebut sangat penting dilakukan sebagai kegiatan yang sangat membantu dan berpengaruh positif terhadap pencapaian pemain tim. Kegiatan kejuaraan ini sebaiknya selalu diadakan agar pemain dan pelatih memiliki pengalaman bertanding yang cukup dalam meningkatkan prestasinya. Kejuaraan tersebut juga dapat melatih kondisi fisik dan psikologi dari pemain tetap terjaga sehingga menghasilkan tujuan yang maksimal. Kegiatan ini dapat dimaksimalkan lagi dengan manajemen yang lebih professional lagi baik agar kualitas kejuaraan menjadi lebih maksimal lagi. Yang terpenting dari kegiatan ini mampu membantu pemain dan pelatih ddalam mengukur kemampuan bermain dan tingkat dari psikologi pemain dalam mengikuti sebuah pertandingan. Saran untuk kegiatan pengabdian masyarakat selanjutnya jika melakukan kegiatan yang serupa, yaitu :

1. Dipertandingkan kelompok umur untuk kejuaraan bulutangkis.

2. Nomor pertandingan ditambah lagi dengan nomor ganda.

\section{Daftar Referensi}

Pratomo dkk.2013. Perbedaan Hasil Latihan Umpan Balik Lob Langsung dan Lob Tak Langsung Terhadap Ketepatan Lob dalam Olahraga Bulutangkis di PB Tugu Muda Kota Semarang. Journal of Sport Sciences and Fitness. Vol. 2, No.1. https://journal.unnes.ac.id/sju/index.php/jssf/article/view/1865

Wijaya,A.2017. Analisis gerak keterampilan servis dalam permainan Bulutangkis (suatu tinjauan anatomi, fisiologi, dan biomekanika ). Indonesia Performance Journal Vol.1 No.2 (2017) http://journal2.um.ac.id/index.php/jko/article/view/2466/1486.

Hapilan, P dkk. 2017. Perbandingan tingkat kecemasan pelatih Dan atlet taekwondo Jurnal Terapan IImu Keolahragaan 2017 Vol.02 No.01.Halaman 38-43.

Jamaliah,N dkk.2015. Pengaruh Hypnotherapy Dan Tingkat Kecemasan Terhadap Konsentrasi Atlet Putri Club Pekerjaan Umum (Pu) Deli Serdang Sumatera Utara Tahun 2015. Journal of Physical Education and Sports.Vol 4.No.2.2015. http://journal.unnes.ac.id/sju/index.php/jpes

Pradnyaswari dan Budisetyani.2018.Hubungan Kecerdasan Emosional Dengan Kecemasan Bertanding Pada Atlet Softball Remaja Putri Di Bali. Jurnal Psikologi Udayana 2018, Vol.5, No.1,218-225. https://simdos.unud.ac.id/uploads/file_penelitian.pdf

Zulfan Maulana, Maya Khairani.2017. Perbedaan Kecemasan Bertanding Pada Atlet Pon Aceh Ditinjau Dari Jenis Aktivitas Olahraga. JIPT. Vol. 05, No.01, Januari 2017. http://ejournal.umm.ac.id/index.php/jipt/article/viewFile/3814/4337 